Arab World English Journal (AWEJ) $2^{\text {nd }}$ Special Issue on Covid 19 Challenges January 2022 DOI: https://dx.doi.org/10.24093/awej/covid2.14

\title{
Transition to Online EFL Teaching in Saudi Arabian Universities during the COVID-19 Outbreak
}

\author{
Saad Eid Albaqami \\ English Language Department \\ Faculty of Sciences and Arts, Albaha University, Saudi Arabia \\ \&
}

School of Education, Communication and Language Sciences, Faculty of Humanities \& Social

Sciences, Newcastle University, United Kingdom

Corresponding Author: salbogami@bu.edu.sa

\author{
Dhaif Alzahrani \\ English Language Department \\ King Khalid University, Abha, Saudi Arabia
}

Received:10/5/2021

Accepted: 12/21/2021

Published:1/24/2022

\begin{abstract}
As a result of the coronavirus crisis and the new restrictions and mandates set by governments around the globe, many educational institutions decided to suspend in-person classes and replace them with online instruction. Universities in Saudi Arabia shifted their entire delivery of teaching to the online platform and closed their doors. This unprecedented and unexpected online transition had several consequences. The present paper examines how instructors in Saudi universities reflected on this transition and the extent to which they were ready for such an unforeseen change. The current study is significant for helping instructors rise to the challenges resulting from the wholescale and ongling transition to online teaching and learning in the wake of COVID-19 and the subsequent suspension of face-to-face instruction. In addition, this study seeks to examine the attitudes and readiness of participants from eight universities in Saudi Arabia in the broader context. The results revealed that instructors have positive attitudes towards utilising online tools and were knowledgeable of the significant advantages of integrating online tools and content into their teaching of English language as a foreign language. (EFL); however, they reported that they were not adequately prepared and that they experienced distress and suffered due to the obligation to acquire new digital skills within a very short period.
\end{abstract}

Keywords: instructors' attitudes, instructors' readiness, COVID-19, online transition, Saudi universities, English language teaching

Cite as: Albaqami, S. E., \& Alzahrani, D. (2022). Transition to Online EFL Teaching in Saudi Arabian Universities during the COVID-19 Outbreak. Arab World English Journal (AWEJ) $2^{\text {nd }}$ Special Issue on Covid 19 Challenges (2) 216-232.

DOI: https://dx.doi.org/10.24093/awej/covid2.14 


\section{Introduction}

As Saudi universities and universities across the globe responded to the outbreak of the Coronavirus pandemic in 2019 (henceforth COVID-19) by closing their campuses and shifting completely to online platforms to deliver their content, many universities and instructors were scrambling to develop online plans for teaching. This transition is assumed to have been challenging for many university instructors who needed to teach online, as they had little or no experience of online teaching; therefore, this paper examines university instructors' attitudes towards and readiness for the transition to online teaching in Saudi universities during the COVID-19 outbreak.

This paper is useful for helping instructors rise to the challenges of teaching in the wake of the transition to online instruction and learning which was forced on education during the COVID-19 pandemic and the wholescale disruption to face-to-face teaching. The paper explores the attitudes and preparedness of a number of instructors from different institutions of higher education in Saudi Arabia. Adopting diverse methods for the investigation gave the results robust validity. The paper focused on university English-language teachers instead of students, concentrating especially on instructors' readiness and experiences concerning online instruction.

\section{Research Questions}

The current research aimed to provide answers to the following questions:

1. What have been Saudi university EFL instructors' attitudes towards the transition to online instruction over the COVID19 period?

2. To what extent were Saudi university English foreign language instructors prepared for the transition to online instruction during the COVID19 period?

\section{Literature Review}

\section{Digital Literacy Practices in Saudi Universities}

The term 'digital literacy' is associated with the set of distinct competencies and educational practices that a user should acquire in order to operate in a modern digital environment (Leaning, 2019). It is commonly used to refer to his or her "ability to understand information and - more important - to evaluate and integrate information in multiple formats that the computer can deliver" (Gilster, as cited in Pool, 1997, p. 6). Within the context of EFL education, multiple recent studies have focused on teachers' digital literacy skills and how they relate to their practices (Jiang \& Yu, 2021), how the 'emergency' transition during COVID has impacted teachers' digital literacy skills (Denardi, Marcos, \& Stankoski, 2021), and teachers' engagement with assessment (Zou, Kong, \& Lee, 2021) and with digital compsing (Jiang, Yu, \& Zhao, 2021).

It is worth examining the perception and influence of digital literacy practices in Saudi universities, as statistics indicate a growing number of digital and social media users amongst young Saudis (Albawardi, 2017). Numerous studies have examined digital literacy practices and have scrutinised blended learning in Saudi universities, particularly the utilization of social media platforms such as Twitter (Alshahrani \& Al-Shehri, 2012; Ahmad, 2015; Kutbi, 2015), Facebook and email (Mahmoud, 2013). Most of the studies were conducted to investigate university students' digital literacy and how they performed with the integration of new digital platforms for education. Allam and Elyas (2016) conducted a study to survey Saudi university 
instructors' attitudes towards the integration of social media in their classrooms. The majority of the participants expressed their enthusiasm for adopting new technologies and stated that, with some reservations, it was vital to implement social media and other new technologies in Saudi universities. Of note, in a study conducted by Al Khateeb (2017) that aimed to measure university instructors' digital competence quantitatively, the outcomes revealed that the majority of the participants were not sufficiently digitally competent. Although this study did not include a qualitative analysis to provide a deeper understanding of the instructors' digital literacy inadequacies, its findings call for more investigation into the phenomenon.

\section{The System of Learning Management in Universities}

It is apparent that the prevalent employment of the internet and technological tools has made the learning management sytems in educational institutions such as universities and schools more vibrant and enriched to become more inclusive. The reason is the availability of the technological infrastructure online (West, Waddoups, \& Graham, 2007). Plentiful learning resources have been created that suit all types of learners through the online learning environment, as well as interactive learning environments for both students and instructors. This online-learning system gives learners autonomy and allows students and instructors to react to each other at any time and anywhere (Cavus, 2007; Levy \& Stockwell, 2006). Therefore, the present COVID-19 crisis has forced schools and universities across the globe to resort to online teaching.

\section{Attitudes towards Online Teaching}

The availability and use of online teaching have become widespread. Besides enumerating its advantages for teaching practice, it would be beneficial to determine how instructors perceive the utilisation of online instruction. Several studies of instructors' attitudes towards online teaching have been conducted.

Alanazy (2018) conducted a study involving 156 faculty members' attitudes towards online learning at Aljouf University, Saudi Arabia. This was a quantitative study that used a questionnaire to explore the instructors' attitudes and demonstrated that faculty members had positive attitudes towards online learning.

(Khamis Ibrahim, Aldhafeeri, Ghareeb Mohamed, Mane Aldhafeeri, \& Alqdah, 2019) explored instructors' attitudes to online teaching using the online version of a blackboard. One hundred and seventy-four instructors at Hafr Al-Batin University participated in an online questionnaire. The quantitative analysis revealed that the instructors had positive attitudes towards the implementation of online teaching.

In a similar study, Dashtestani (2014) used both a questionnaire and semi-structured interviews to gauge Iranian EFL instructors' perceptions of and attitudes towards implementing online instruction. The study concluded that, although the instructors had positive attitudes towards online instruction, they believed that instruction should be blended rather than being completely online. The study also revealed that there was cultural resistance, and that the instructors lacked knowledge and had insufficient training, which implemented online instruction more problematic and challenging. Similarly, Canals and Al-Rawashdeh (2019) carried on a study to explore instructors' attitudes towards the use of online EFL courses in Jordanian 
universities. A number of EFL instructors responded to both a questionnaire and a structured interview, and reported contradictory feelings about implementing online instruction, as it was considered to be more helpful for them to practice listening and reading than it is for speaking and writing (receptive vs. productive skills). The study also concluded that the instructors lacked sufficient digital skills and required more training prior to implementing online instruction.

A few studies of instructors' attitudes during the COVID-19 pandemic have been conducted. Mishra, Gupta and Shree (2020) investigated instructors' and students' perceptions of online teaching during COVID-19 and identified some of the challenges that students and instructors faced, such as weak Internet connections and video problems. Another study carried out by Rasmitadila et al. (2020), examining the experiences of primary school instructors teaching online during the COVID-19 pandemic. The findings indicated that instructors experienced unpleasant impacts of online teaching practices such as technical failures, dissimilar learners' circumstances, affordability issues, as well as the lack of motivation and learners' involvement. Consequently, as the aforementioned studies conducted throughout the COVID-19 pandemic focused on primary schools and universities that were offering different majors, the current study focused on the instructors who were teaching English as a major.

\section{Readiness for Online Teaching}

Due to the increase in the number of online courses available, it is essential for any university or school to be prepared for teaching online, particularly during the present crisis. A few studies of instructors' readiness for online teaching have been conducted, as Martin, Wang, Jokiaho, May and Grübmeyer (2019) stated. Gay (2016) investigated the evaluation of online teachers' e-learning readiness before the course started, then during and after the course. The study revealed that the availability of help desk services was an important requirement for online tutors. Moreover, another study found that university instructors did not feel sufficiently ready to teach online (Lichoro, 2015). According to Downing and Dyment (2013), who investigated instructor educators' readiness and instructors' experiences to prepare preservice instructors in a completely online setting, the instructors considered online education to be time consuming; moreover, they observed that instructors who were new to online teaching did not feel ready to teach online and required technological and educational support, as well as methods for time management.

In addition, Mohalik and Sahoo (2020) conducted a study during the COVID-19 pandemic in order to examine instructors' readiness and experiences of online teaching; they found that instructors were not ready to teach online when they had poor Internet connections, an insufficient electricity supply and lacked a private area at home. They did not feel happy and had reduced confidence in teaching online.

Against this background, the present study aims to fill this gap by investigating instructors' attitudes to and readiness for online teaching during the suddenly forced transition to online teaching due to the COVID19 outbreak. The study is significant for exploring how instructors rose to the challenges resulting from this sudden switch in the delivery of teaching to being completely remote via the use of varied online platforms throughout the COVID-19 period and the unexpected interruption in face-to-face teaching. This study investigates the attitudes to and the readiness of instructors in the context of higher education in Saudi Arabia. Adopting 
diverse methods for the investigation endowed the results with a high degree of reliability and validity. The study concentrated on university English-language instructors rather than students, with a particular focus on their readiness and experiences with regard to online teaching.

\section{Methods \\ Participants}

The current study employed a sequential explanatory design methodology (Creswell \& Clark, 2017) encompassing two research methods, namely a closed-ended questionnaire and oneto-one semi-structured interviews. In total, $69 \mathrm{EFL}$ university instructors teaching EFL at different Saudi universities participated in the questionnaire. The participants were from eight Saudi universities, namely Albaha University, King Khalid University, King Saud University, Princess Nourah University, Taibah University, Taif University, Umm Al-Qura University and the University of Bisha.

\section{The research tools}

The questionnaire was distributed to and completed by the participants online and was intended to gauge their attitudes towards and readiness for the transition to online teaching in Saudi universities during the COVID-19 pandemic. The questionnaire was adapted from those used in other studies (e.g. Schmidt et al., 2009; Kaalberg, 2014). The survey was followed by one-to-one semi-structured interviews with 10 university EFL instructors who had expressed a willingness to take part. The interviews were conducted online via the Zoom communication app due to social distancing restrictions, which prevented face-to-face interviews. Researchers have used videoconferencing methods, such as Zoom, as an alternative means of qualitative data collection as these methods provide valuable opportunities to collect data while observing social distancing mandates and/or very long distances (Lobe, Morgan, \& Hoffman, 2020).

To examine the reliability of the questionnaire exploring the participants' attitudes towards and readiness for the transition to online teaching in Saudi universities during the COVID-19 outbreak, we calculated Cronbach's alpha and conducted it utilising SPSS software for the whole scale, excluding the demographic section. As is noticed in Figure 1, the resulting score was .894, which shows a high level of internal consistency of reliability according to Cronbach (Nunnaly, 1978).

\section{Research procedures}

\begin{tabular}{r|r} 
Cronbach's Alpha & N of Items \\
\hline .894 & 37 \\
\hline
\end{tabular}

Figure 1.Reliability Statistics

The data gathered from the questionnaire were coded and input into SPSS to explore instructors' attitudes towards and aptitude for the transition to online teaching in Saudi universities during the COVID-19 outbreak. The analysis allowed for graphical representations to be provided to demonstrate the instructors' attitudes and aptitude. The quantitative questionnaire was a useful tool for collecting numerical data to evaluate the attitudes and aptitude of the instructors. The format was a five-part Likert scale varying from 1 ('strongly disagree') to 5 ('strongly agree' in response to specific statements regarding the instructors' attitudes and readiness. Biographical information obtained via the questionnaire included 
university degree, age, gender and years of teaching online. The findings were analysed and displayed as figures, bar charts and graphs.

\section{Findings}

\section{Descriptive Statistics for the Participants}

The participants were given three options to describe their amount of experience in teaching online, which were: 1) less than five years, 2) between five years and ten years and 3) more than ten years. The findings showed that $89.9 \%$ of the instructors had less than five years of online instruction experience, which confirmed that the instructors had little online instruction experience before COVID-19. Moreover, $56.5 \%$ of the instructors had a PhD, while $34.8 \%$ had a master's and $8.7 \%$ had a bachelor's. Of the participants in the current study, $73.9 \%$ were male and $26.2 \%$ were female; furthermore, $50.7 \%$ were over the age of 40 and $39.1 \%$ were aged between 30 and 40 years. Only $10.1 \%$ were younger than 30 years of age.

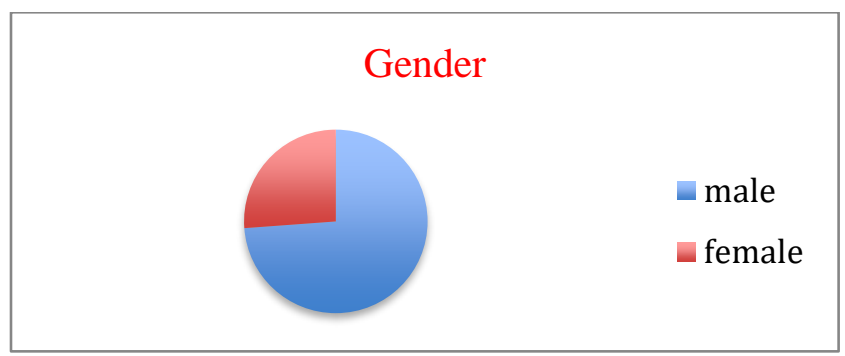

Figure 2. Participants' genders

\section{Descriptive Statistics for the Instructors' Attitudes towards and Readiness for Online Teaching}

The instructors' attitudes towards and readiness for teaching online were measured via a 31-item survey using a five-point Likert scale to calculate the mean scores for the entire scale and two sub-scales. The scale ranged from one to five; a rating of one indicated a lack of readiness and negative attitudes, and a rating of five indicated readiness and positive attitudes. Table one presents the instructors' attitudes towards and readiness for online teaching as indicated by the survey tool, which quantified the overall readiness and attitudes, as well as the sub-dimensions.

Table 1. Instructors' attitudes towards and readiness for online teaching

\begin{tabular}{c|ccc}
\hline & $N$ & $M$ & $S D$ \\
\hline Attitudes towards online teaching & 69 & 3.54 & 1.11 \\
Readiness for online teaching & 69 & 2.68 & 1.16 \\
\hline
\end{tabular}

Table one shows that, on average, the instructors reported positive attitudes towards online teaching with a mean score of $3.54(S D=1.11)$, but did not feel ready to teach online $(M$ is 2.68, $S D$ is 1.16). It appears that, overall, the majority of the instructors had a positive attitude towards online teaching, but did not feel ready to do so. Therefore, the next two tables present each dimension separately, namely attitudes towards and readiness for online teaching.

Table two below illustrates the frequency of the instructors' responses to the Likert items illustrating their attitudes towards online teaching. It is clear that the majority of the instructors 
Arab World English Journal (AWEJ) 2nd Special Issue on Covid 19 Challenges January 2022

Transition to Online EFL Teaching in Saudi Arabian Universities

Albaqami \& Alzahrani

strongly agreed with most of the items, except for 'face-to-face classes should be replaced with online teaching' and 'students are more active online than in face-to-face settings'.

Table 2. Instructors' attitudes towards online teaching

\begin{tabular}{|c|c|c|}
\hline I should receive extra training on basic digital literacy skills & 3.88 & 1.12 \\
\hline Conducting and delivering online teaching is enjoyable for me & 3.93 & 1.06 \\
\hline Online teaching can save me time & 3.78 & 1.20 \\
\hline $\begin{array}{l}\text { After the suspension, I believe that face-to-face classes should be replaced with online } \\
\text { teaching }\end{array}$ & 2.64 & 1.42 \\
\hline $\begin{array}{l}\text { After the suspension, I believe that face-to-face classes should be combined with online } \\
\text { teaching }\end{array}$ & 3.90 & 1.07 \\
\hline The use of online platforms enables me to provide more thorough feedback & 3.35 & 1.20 \\
\hline Online materials fulfil my students' demands and match their needs & 3.48 & 1.09 \\
\hline Online teaching offers equal learning opportunities for my students & 3.25 & 1.18 \\
\hline Online teaching promotes my students' autonomous learning & 3.51 & 1.12 \\
\hline I think my students seem to have positive attitudes towards online teaching & 3.45 & 1.04 \\
\hline I think my students should receive extra training in basic digital literacy skills & 4.32 & 0.81 \\
\hline $\begin{array}{l}\text { The transition to online teaching helps to promote instructors' competence in online } \\
\text { instruction }\end{array}$ & 4.10 & 0.83 \\
\hline Online teaching provides opportunities for more collaboration among students & 3.49 & 1.07 \\
\hline In online teaching, students are more active than in face-to-face settings & 2.71 & 1.26 \\
\hline Students' attitudes towards online teaching affect their interaction & 3.75 & 1.08 \\
\hline Online teaching promotes learners' autonomous learning & 3.42 & 1.06 \\
\hline Online teaching offers a more interactive environment for learning & 3.30 & 1.18 \\
\hline
\end{tabular}

However, the item with which the instructors agreed most strongly was 'my students should receive extra training in basic digital literacy skills'. In addition, the instructors disagreed with the item 'face-to-face classes should be replaced with online teaching'.

Table three below shows the frequency of the instructors' answers to the Likert-scale items reflecting their readiness for online teaching. Table three displays that the instructors agreed strongly with the statement 'I can acclimate my instruction style to various students', with a mean score of 3.52 and a standard deviation of 1.35 .

The two statements with which the instructors disagreed strongly were 'All students are able to utilize the online platform efficiently' and 'I was ready for the unforeseen complete transition to online teaching' ( $M$ : 2.03 and 2.30; $S D: 1.01$ and 1.03, respectively).

Table 3. Instructors' readiness for online teaching

\begin{tabular}{|lll|}
\hline I was ready for the unforeseen and entire transition to online instruction & 2.30 & 1.03 \\
\hline Students were ready for the unforeseen and entire transition to online instruction & 2.61 & 1.07 \\
\hline I can acclimate my instruction style to various students & 3.52 & 1.35 \\
\hline All students are able to access online materials easily & 2.61 & 1.49 \\
\hline University courses materials are appropriate to be utilised for online teaching & 2.33 & 1.12 \\
\hline Preparing and uploading online materials and course content are easy & 2.51 & 1.15 \\
\hline Supplementary materials and multimedia can be used easily on the university's & 2.93 & 1.33 \\
\hline
\end{tabular}

Arab World English Journal

WWW.awej.org

ISSN: 2229-9327 
Arab World English Journal (AWEJ) 2nd Special Issue on Covid 19 Challenges January 2022

Transition to Online EFL Teaching in Saudi Arabian Universities

Albaqami \& Alzahrani

\begin{tabular}{|lll|}
\hline online platform & & \\
\hline Available materials used in online teaching are authentic and reliable & 2.36 & 1.12 \\
\hline Available materials are designed based on student-centred approaches to teaching & 2.54 & 1.04 \\
\hline All students are able to utilise the online platform efficiently & 2.03 & 1.01 \\
\hline I know how to evaluate learner performance in a classroom & 2.94 & 1.10 \\
\hline I can adjust my instruction based on what learners now do or do not comprehend & 3.07 & 1.18 \\
\hline I am familiar with ordinary learner understandings and misconceptions & 2.94 & 1.16 \\
\hline I understand how to manage and support classroom management online & 2.81 & 1.10 \\
\hline I can evaluate learner learning in numerous ways & 2.68 & 1.06 \\
\hline
\end{tabular}

The current research utilised a mixed-method approach. The quantitative results were shown earlier, but some questions were not answered; for example, what are the advantages of this unforeseen complete transition to online teaching, what are the most noticeable complications or struggles instructors encountered in online teaching during COVID-19 outbreak, and how did the teachers find the experience of teaching EFL on the platforms they were using?

The quantitative section included statistical interpretations that showed the attitudes towards and readiness for online teaching, but it was considered essential to elaborate on these results qualitatively to obtain a specific evaluation of the instructors' attitudes and readiness.

\section{Descriptive Qualitative Interviews to Determine the Instructors' Attitudes Towards and Readiness for Online Teaching}

The current paper utilised a thematic analysis to analyse the interviews. In order to describe and explain the instructors' feelings towards and readiness for the unforeseen transition to online teaching, the data were initially categorised into themes and were then interpreted to reveal patterns (Bryman, 2008) to provide a better knowledge of the phenomenon under investigation (Braun \& Clarke, 2006). Following this strategy, five prominent themes emerged from the data, namely transition distress, embracing contemporary online teaching skills, accessibility and Internet disruption, effectiveness compared to being present in face-to-face classrooms, and building online communities of practice.

The interviews with the 10 academics revealed that the online transition had multiple advantages and disadvantages. Even though the interviewees came from different backgrounds and worked at different universities, their feelings and experiences of the issue were very similar.

\section{Transition Distress: 'This Was Unpredictable, and I Was Not Prepared'}

A major drawback that the majority of the interviewees represented was their struggle to cope with the entire and sudden transition to online instruction and the need to gain the necessary skills to teach in this way. Amongst the complications related to the online transition listed by the academics were their own limited digital knowledge and limited experience of e-Learning, and the lack of institutional content and course-related materials designed for online delivery, in addition to the students' commitment and involvement suffering. As Adam stated,

The sudden complete shift without sufficient previous experience in e-Learning made it very difficult for me to handle the new situation. I felt frustrated at the beginning and I 
had to exert much effort and spend extra hours improving my personal skills in order to overcome this difficulty.

Similar views were echoed by Salahuddin, who stated, 'This is a completely new situation that necessitates certain skills and proficiencies. I must admit that I spent a great amount of time empowering myself with required digital skills.

On the topic of students' aptitude and motivation, Ahmed stated, 'Students also were not ready for this shift in education. A considerable number of students complained that they didn't have personal computers and couldn't afford to pay for them'. This placed a burden on the instructors as they attempted to adapt the way they delivered the online content and classes, and the way they assessed their students while attempting to maintain fairness. Part of the adaptation was the stress the instructors experienced at the beginning of the shift and the huge amount of work entailed in transferring all the content for online delivery, in addition to the multiple daily announcements and requests from the authorities and stakeholders at the universities. Abdu explained,

We were asked to upload all the materials on the platform and hold both synchronous and asynchronous classes and monitor students' attendance and achievement despite the fact that students were either not serious enough or don't have the ability to cope with this new situation.

The topic of issues with the platforms was also raised by another academic, Salahuddin, who stated, 'Poor infrastructure, platform disruption, and frequent changes and modifications in the timetables were a great concern for me'.

\section{Embracing Contemporary Teaching Techniques and Utilising Online Platforms: 'I Believe I Am Now Able to Utilise Online Platforms More Competently'}

As Mariam reported, 'This whole craziness turned out to be a blessing in disguise.' She explained:

Although we went through anxious and unpleasant times especially at the beginning of the transition, this resulted in an unforeseen positive outcome. I myself had to learn new teaching techniques that would suit the new teaching environment in addition to learning the required digital skills that enable me to run classes professionally.

All the other interviewees agreed that, despite the disadvantages of the unforeseen complete transition to online teaching, the advantages needed to be acknowledged. Adam stated, 'In the past, we used to take this for granted and blended learning is taken as luxury, while now e-Learning has become a dire need'. Fatima added, 'This shift has forced all academics to utilise online platforms and upload the entire content online, which most of us had never done before'.

In addition, Ahmed explained that students used to rely on what was presented by their instructors in face-to-face classes, and that they intentionally ignored the online content. $\mathrm{He}$ clarified that this shift had also impacted on the students because they learned to utilise online platforms more effectively, which would have a great impact on their performance in the future. Ahmed added, 'The authority wouldn't have to issue any decree to suspend education entirely in the future in case of heavy rain, and consequently would rely on the blended and hybrid learning 
instead'. Another advantage of the wake of transition to online instruction was discussed by Musa, who stated that the authorities had to accelerate the reforms to their online infrastructure and identify the latest technological trends in order to meet the students' learning needs. Such accelerated reforms and modifications would not have taken place had such a disruption not occurred. Hassan was of the same opinion; he stated that, although we live in the era of modern technology and the education system has changed dramatically, both the authorities and the instructors had insisted on using old-fashioned teaching strategies and had neglected the integration of online materials in their teaching. However, they had become aware of the significance of online education and hurried to complete all the potential reforms to improve modern instruction strategies. The interviewees thought that online instruction could become an essential part of their educational processes even after the COVID-19 pandemic is over and life returns to normal.

\section{Accessibility and Internet Disruption: 'Everybody Complains About Internet Complications'}

A consensus amongst all the interviewees was that the main problems hindering online teaching were the Internet disconnecting constantly and faulty service. They all expressed feeling frustrated when students were unable to attend online sessions on time or failed to attempt online examinations due to Internet issues. As Adam said, 'I myself often encounter on-going Internet lag which is a very frustrating problem'. Poor Internet connectivity and very slow speed affected the delivery of synchronous virtual classes and delayed the communication between learners and instructors. Moreover, as Salahuddin stated, it hampered the application of several teaching strategies. Mariam confirmed that the poor Internet connection contributed to students from rural areas and distant villages falling behind academically. 'A significant number of my students were unable to attend virtual classes, especially in the first two weeks of transition, due to Internet connectivity issues', Fatma said.

Of note, two academics associated the students' performances in their courses with Internet speed and digital skills. Zahra argued that students with good Internet connectivity had considerably better digital skills, as demonstrated by their exam results. Similarly, Adam believed that home Internet access contributed to greater digital skills; thus, students with fewer digital skills were prone to worse performances than were their peers. This caused great concern for the instructors, who needed to seek alternative assessment methods in order to ensure fairness amongst all the students.

Ahmed noted that most of the students tended to use their smartphones and struggled to utilise the resources available on the online platform or on any other website, possibly due to the slow data connectivity of local service providers.

\section{A good experience but not equivalent to being present in class: 'I enjoyed it but not as much as face-to-face classrooms'}

The participants expressed that they enjoyed the distinctive experience of teaching online, particularly at the beginning of the transition and when all the functions were available. However, they stated that online teaching could not replace being present in class, as there were substantial differences between the two settings. Musa stated, 
Online teaching is interesting, and my experience is amazing despite all the suffering in the beginning and the troubles my students and I went through. Though, I am nostalgic for traditional face-to-face classroom teaching where I can feel the intimacy between me and my students.

Maryam agreed, saying:

I just cannot help it. Although online teaching is easier in terms of content delivery, I find myself in favour of traditional classroom instruction for several reasons: Firstly, I am able to communicate with my students straightforwardly without any mediators. Secondly, the burden of ensuring that there is a sense of socialisation and inclusion is alleviated.

As Ahmed said,

Compared to face-to-face teaching, online instruction facitliates some facets, including the availability of materials, innovative strategies, and flexible attendance from anywhere. However, it can not supersede face-to-face instruction, in which instructors feel more comfortable dealing with their students without any burden.

By contrast, Maha stated,

I genuinely didn't enjoy teaching online whatsoever. I find it very tedious and energy sapping for both instructors and students. I myself developed back pain and experienced eye twitching due to sitting for a long period in front of the laptop screen. My students also complain that classes took longer time than normal although the duration never changed. I also cannot enhance students' engagement as I used to do in traditional classroom teaching. I honestly find it extremely boring for students and instructors.

There was some consensus amongst the interviewees that, compared to being present in class, online teaching was less enjoyable and less effective. The feeling of boredom and the struggle to create an engaging atmosphere were more apparent in the online context than in face-to-face teaching.

\section{Building online communities of practice is imperative: 'I feel isolated'}

Four academics expressed their eagerness and enthusiasm to participate in online communities of university instructors who shared the same interests and worked in the same manner. They emphasised the importance of participation in such a community based on a number of reasons. Ahmed stated,

I encourage all my colleagues to look for the many online groups of online instructors and join to have the sense of community. I believe this is very important to share knowledge and exchange creative ideas as online teaching is changing and there are creative instructors who would help.

This opinion was echoed by other academics; Maha supported participating in a community of practice, stating that it was not only a way to share knowledge, but was essential for those who suffer from isolation. Maha clarified that she used to feel that she was alone until 
she joined online instructors' sessions and found that most of the instructors had the same concerns and worries; this gave her a sense of comfort and reassurance, and provided her with more motivation. As Adam confirmed,

Connecting with peers is essential. It is an amazing opportunity from which you can learn new teaching skills and adopt innovative ideas. In the meantime, all of the instructors across the world were forced to shift to online teaching due to the pandemic outbreak, and this is an opportunity that may not be repeated where you can find online communities sharing the same distresses.

The fourth academic to share this view was Salahuddin who stated:

This sudden and unprecedented transition to entire online delivery of teaching is indeed not a luxury. We often feel exhausted and self-isolated although we are connected with our students. You sometimes need a supporting community that supportive community to motivate you and immunises you against the dreadful sentiment of loneliness and boredom. It also goes without saying that building a community fosters a mutual engagement around the most shared topics and contributes to avoiding burnout.

It could be said that all four of the academics who mentioned this theme were conscious of the significance of participating in a community of practice and provided several justifications for doing so. According to them, participating in a community of practice is an excellent way to combat teachers' feelings of isolation, and to remain motivated and supported, in addition to its effectiveness in the circulation of innovative teaching practices, the exploration of ideas, and the best utilisation of the advantages of online environments.

\section{Discussion}

The present study examines how instructors in Saudi universities have reflected on the transition to online teaching and the extent to which they were ready to do so. The first question was designed to examine university instructors' attitudes towards the transition to online teaching.

The findings from the quantitative data, comprising a total of 69 particpants, indicate that the instructors had positive experiences and were enthusiastic about the adoption and utilization of online teaching in general and about the application of varied online tools in particular. These findings are consistent with those of Ibrahim et al. (2019), Alanazy (2018) and Dashtestani (2014), whse research revealed positive attitudes towards teaching online. However, most of the instructors exhibited their dissatisfaction with the learners' involvement and particiapation and demanded that further concentrated training sessions in digital literacy skills be held for the learners.

The interview with the ten university instructors revealed further thought-provoking accounts regarding their viewpoints on the application of the online delivery of teaching as well as their learners' involvement and inclusion. Such responses were coded into themes that comprised internet accessibility and disruption, effectiveness in comparison to being present in face-to-face classrooms, and building online communities of practice. The instructors were content that, although they suffered initially, their performances did improve substantially. This finding is in line with the study by Allam \& Elyas (2016), which revealed that instructors felt 
enthusiastic about adopting new online tools and believed they derived valuable pedagogical benefits from the switch. Such a finding was also reported in Canals and Al-Rawashdeh's (2019) study, which reported that instructors' employment of online tools in their teaching delivery has remarkably advanced their mastery of new digital literacy skills.

The participants also revealed that the advantages of online instruction did not preclude the complications associated with the new tools. Major difficulties were related to the accessibility of the Internet and the Internet connection dropping. This hindered the smooth flow of online instruction and caused a cetain a amount of discomfort for both instructors and students. In the fourth theme, the participants reported positive attitudes towards the use of online tools and the abundant benefits of the integration of online tools and content in EFL teaching. However, they expressed reservations about a potential permanent move to online teaching and relying entirely on online platforms after the COVID-19 pandemic. This finding supports that of Dashtestani (2014), who asserted that in-person teaching is requisite and indispensable and therefore cannot be substituted by complete online delivery of teaching; however, online teaching should be utilized as supplementary to in-person teaching. Besides, almost all of the instructors reflected on their feelings of loneliness and isolation during the online teaching experience, unlike standard in-person teaching, where they are surrounded by students and peers in the 'real physical world'. They emphasised the significance of building support bubbles and expressed eagerness to participate in online communities of practice. They considered that this would have several advantages, such as sharing knowledge and keeping abreast of innovative ideas. They also highlighted the necessity of discussing their expectations and concerns with peers, which would alleviate the discomfort they felt during such a difficult and stressful time.

The second question aimed to examine the instructors' readiness and extent to which they were prepared for the unexpected transition to online teaching. A number of studies have been conducted on instructors' readiness for online teaching (e.g. Martin et al., 2019; Gay, 2016; Lichoro, 2015; Downing \& Dyment, 2013), revealing that teachers did not feel ready to teach online before COVID-19. In addition, a small number of studies have been carried out during the COVID-19 pandemic. For example, a study by Mohalik and Sahoo (2020) found that instructors felt negatively about their readiness. The authors focused on a variety of majors while the current study focuses exclusively on instructors teaching English as a major.

In terms of the quantitative analysis in the current study, overall, the instructors reported not feeling ready to teach online; the statement with which the instructors agreed most strongly was 'I can acclimatise my instruction style to various students', while the two items with which the instructors disagreed most strongly were 'All students are able to utilise the online platform efficiently' and 'I was ready for the unforeseen entire transition to online instruction'. Consequently, as the instructors were not prepared for the unexpected and wholescale shift to online teaching, this study's findings concur with the findings of the aforementioned studies in the literature.

In terms of the qualitative analysis, the themes that emerged from the interviews with 10 university instructors were transition distress and embracing contemporary online teaching skills. Al Khateeb (2017) concluded that English-language instructors in Saudi universities lack 
adequate digital literacy. This finding was echoed in the present study, as the participants explained that they experienced distress and struggled to acquire new digital skills within a very short period of time to support the transition. The current study provided qualitative data explaining how the instructors' limited digital skills influenced the smooth transition to online teaching, as well as how it affected their adaptation to the sudden change. These findings are also consistent with those in the literature review (Lichoro, 2015; Dyment, 2013; Dashtestani 2014; Canals \& Al-Rawashdeh, 2019) concerning instructors' inadequate preparation and readiness, the necessity of offering more training in digital skills for instructors, and the distress they felt as a result of their insufficient digital proficiency. Furthermore, the findings provided evidence that the infrastructure was not ready for a quick transition to online teaching, placing an extra burden on instructors due to technical issues during the switch and the consequences thereof. This reinforces the necessity of providing 'instant help desks' and offering support from universities' technical teams at universities, as stated by Gay (2016).

The current study's results align with earlier studies (Ibrahim et al., 2019; Alanazy, 2018; Dashtestani, 2014) regarding the instructors' positive attitudes towards online teaching. However, it is congruent with Al Khateeb (2017) that instructors had insufficient digital literacy competencies, which affected their instructional practices and feelings of distress. Nevertheless, the instructors stated that this sudden change was a blessing in disguise in the sense that it forced them to acquire and utilise the most contemporary teaching techniques and strategies.

\section{Conclusion}

This study is essential for enabling instructors to rise to the challenges resulting from the unexpected transition to online teaching in Saudi universities due to the spread of COVID-19 and the new mandates enforced by the country's government. The study aimed to investigate instructors' attitudes and readiness in a broad context, with the participants hailing from eight different universities across Saudi Arabia. It was concluded that the instructors had positive attitudes towards online teaching, reflecting on the abundant advantages of the integration of online tools and content in EFL teaching. However, the data also indicated that the instructors were not adequately prepared for this unexpected shift, and that they lacked the necessary digital skills to adapt to the new circumstances. The participants also reported that this unexpected shift and the new regulations placed extreme pressure on them, making them feel distressed, and that they struggled to gain new digital skills rapidly in order to support the transition. It is concluded that the present paper could be of significant value in comprehending how university instructors responded to the online transition and how they felt about it. The study makes It clear that the instructors required extra preparation beforehand, findings which could help Saudi universities offer the required assistance to their faculty members, including training sessions, an 'instant help desk service', supportive academic communities, and the like. The results also provide useful guidance for policy makers and university instructors, giving them information that could be used to identify and appreciate both the benefits and the shortcomings of integrating online platforms in teaching and to provide the necessary digital and technical skills.

Overall, additional studies that highlight university instructors' readiness for teaching online are recommended. Furthermore, future studies are necessary to investigate the benefits and drawbacks of the online tools that have already been approved and are being used by universities in Saudi Arabia. It is also recommend that universities in Saudi Arabia fund similar 
Arab World English Journal (AWEJ) 2nd Special Issue on Covid 19 Challenges January 2022

studies that contribute to assisting policy makers and instructors to understand the effectiveness of existing teaching practices and current instructional tools.

\section{Acknowledgements}

The authors would like to offer their sincere gratitude to all the university instructors who volunteered to take part in this study. In addition, the authors would like to express their gratitude to the anonymous reviewers for their feedback and suggestions.

\section{About the Authors:}

Saad Eid Albaqami is a lecturer in the Department of English at Albaha University, Saudi Arabia. His research merges the fields of applied linguistics and educational technology and focuses on the implementation of language instruction, pedagogical practices and vocabulary acquisition. ORCID: https://orcid.org/0000-0003-4418-2101

Dhaif Alzahrani is a Ph.D. candidate in educational and applied linguistics at Newcastle University, UK. He is a lecturer at English language department, King Khalid University, Saudi Arabia. His research focuses on the impacts of mediational means on L2 collaborative writing. $\mathrm{He}$ is interested in technology-enhanced language learning and multimodal communication in L2 classrooms. ORCID: https://orcid.org/0000-0002-8673-5504

\section{References}

Ahmad, M. (2015). The Effect of Twitter on Developing Writing Skill in English as a Foreign Language. Arab World English Journal, $134-149$ https://dx.doi.org/10.2139/ssrn.2843985

Al Khateeb, A. A. M. (2017). Measuring Digital Competence and ICT Literacy: An Exploratory Study of In-Service English Language Teachers in the Context of Saudi Arabia. International Education Studies, 10(12), 38-51.

Alanazy, S. M. (2018). Factors Affecting Faculty Attitude for Adopting Online Learning at Aljouf University, Saudi Arabia. Journal of Education and Learning, 7(1), 154-162.

Albawardi, A. (2017). Digital literacy practices of female Saudi university students: insights from electronic literacy logs. Language Studies Working Papers, 8, 12-22.

Allam, M., \& Elyas, T. (2016). Perceptions of Using Social Media as an ELT Tool among EFL Teachers in the Saudi Context. English Language Teaching, 9(7). https://doi.org/10.5539/elt.v9n7p1

Alshahrani, K., \& Al-Shehri, S. (2012). Conceptions and responses to e-learning: The case of EFL teachers and students in a Saudi Arabian university. Monash University Linguistics Papers, 8(1), 21. https://search.informit.org/doi/abs/10.3316/INFORMIT.671764122005636

Canals, L., \& Al-Rawashdeh, A. (2019). Teacher training and teachers' attitudes towards educational technology in the deployment of online English language courses in Jordan. Computer Assisted Language Learning, 32(7), 639-664. https://doi.org/10.1080/09588221.2018.1531033

Cavus, N. (2007). Assessing the success rate of students using a learning management system together with a collaborative tool in Web-Base teaching of programming languages. Journal of Educational Computing Research, 36(3), 301-321. https://doi.org/10.2190\%2FT728-G676-4N18-6871 
Arab World English Journal (AWEJ) 2nd Special Issue on Covid 19 Challenges January 2022

Creswell, J. W., \& Plano Clark, V. L. (2017). Designing and Conducting Mixed Methods Research | SAGE Publications Ltd. In SAGE Publications, Inc. Retrieved from https://uk.sagepub.com/en-gb/eur/designing-and-conducting-mixed-methodsresearch/book241842

Dashtestani, R. (2014). English as a foreign language - Teachers' perspectives on implementing online instruction in the Iranian EFL context. Research in Learning Technology, 22(1), 1-15. https://doi.org/10.3402/rlt.v22.20142

Denardi, D. A. C., Marcos, R. A., \& Stankoski, C. R. (2021). Impacts from Covid-19 pandemic in English language classroom. Ilha Do Desterro, 74(3), 113-143. https://doi.org/10.5007/2175-8026.2021.E80733

Downing, J. J., \& Dyment, J. E. (2013). Teacher educators' readiness, preparation, and perceptions of preparing preservice teachers in a fully online environment: An exploratory study. The teacher educator, 48(2), 96-109. https://doi.org/10.1080/08878730.2012.760023

Gay, G. H. (2016). An assessment of online instructor e-learning readiness before, during, and after course delivery. Journal of Computing in Higher Education, 28(2), 199-220. https://doi.org/10.1007/s12528-016-9115-z

Ibrahim, L. K., Mohamed, A. G., Aldhafeeri, F. M., \& Alqdah, M. (2019). Faculty members' perceptions towards utilizing blackboard in teaching system at Hafr Al-Batin University, Saudi Arabia. Journal of Nursing Education and Practice, 9(5). 64 - 74

Jiang, L., \& Yu, S. (2021). Understanding Changes in EFL Teachers' Feedback Practice During COVID-19: Implications for Teacher Feedback Literacy at a Time of Crisis. Asia-Pacific Education Researcher, 30(6), 509-518. https://doi.org/10.1007/S40299-021-00583-9

Jiang, L., Yu, S., \& Zhao, Y. (2021). Teacher engagement with digital multimodal composing in a Chinese tertiary EFL curriculum. Language Teaching Research, 25(4), 613-632. https://doi.org/10.1177/1362168819864975

Kaalberg, Kyle F. (2014). "Enhancing Teaching and Learning through iPad Integration in a Clinic- based Literacy Course." https://digitalscholarship.unlv.edu/thesesdissertations/2101/

Khamis Ibrahim, L., Aldhafeeri, F., Ghareeb Mohamed, A., Mane Aldhafeeri, F., \& Alqdah, M. (2019). Faculty members' perceptions towards utilizing blackboard in teaching system at Hafr Al-Batin University, Saudi Arabia. Researchgate.Net5)9,). https://doi.org/10.5430/jnep.v9n5p64

Kutbi, A. I. (2015). How Undergraduate Female Students in the Kingdom of Saudi Arabia Perceive Social Media as a Learning Tool: An Exploratory Study. http://scholar.uwindsor.ca/cgi/viewcontent.cgi?article=6289\&context=etd

Leaning, M. (2019). An Approach to Digital Literacy through the Integration of Media and Information Literacy. Media and Communication, 7(2), 4-13. https://doi.org/10.17645/MAC.V7I2.1931

Levy, M., \& Stockwell, G. (2006). CALL Dimensions: Options and issues in computer assisted language learning. Mahwah, NJ: Lawrence Erlbaum.

Lobe, B., Morgan, D., \& Hoffman, K. A. (2020). Qualitative Data Collection in an Era of Social Distancing. International Journal of Qualitative Methods, 19, 160940692093787. https://doi.org/10.1177/1609406920937875

Lichoro, D. M. (2015). Faculty preparedness for transition to teaching online courses in the Iowa Community College Online Consortium. 
Arab World English Journal (AWEJ) 2nd Special Issue on Covid 19 Challenges January 2022

Lobe, B., Morgan, D., \& Hoffman, K. A. (2020). Qualitative Data Collection in an Era of Social Distancing. International Journal of Qualitative Methods, 19, 1 - 8. https://doi.org/10.1177/1609406920937875

Mahmoud, S. S. (2014). Email and Facebook to Promote Foundation Year Students' EFL Writing at King Abdul-Aziz University. International Review of Social Science and Humanities, 6(2), 157-172.

Martin, F., Wang, C., Jokiaho, A., May, B., \& Grübmeyer, S. (2019). Examining Faculty Readiness to Teach Online: A Comparison of US and German Educators. European Journal of Open, Distance and E-learning, 22(1). 53 - 69

Mishra, L., Gupta, T., \& Shree, A. (2020). Online teaching-learning in higher education during lockdown period of COVID-19 pandemic. International Journal of Educational Research Open, 1, 100012. 1- 8

Mohalik, R. and Sahoo, S. (2020). E-Readiness and Perception of Student Teachers' Towards Online Learning in the Midst of COVID-19 Pandemic. Available at https://dx.doi.org/10.2139/ssrn.3666914.

Nunnally, J. C. (1967). Psychometric Theory (1st ed.). New York: McGraw-Hill.

Rachmadtullah, R. et al. (2020). The Perceptions of Primary School Teachers of Online Learning during the COVID-19 Pandemic Period: A Case Study in Indonesia. Journal of Ethnic and Cultural Studies, 7(2), 90-109.

Schmidt, D.A. et al. (2009). Technological pedagogical content knowledge (TPACK) the development and validation of an assessment instrument for preservice teachers. Journal of research on Technology in Education, 42(2), pp.123-149. https://doi.org/10.1080/15391523.2009.10782544

West, R. E., Waddoups, G., \& Graham, C. R. (2007). Understanding the experiences of instructors as they adopt a course management system. Educational Technology Research and Development, 55(1), 1-26. https://doi.org/10.1007/s11423-006-9018-1

Zou, M., Kong, D., \& Lee, I. (2021). Teacher Engagement with Online Formative Assessment in EFL Writing During COVID-19 Pandemic: The Case of China. Asia-Pacific Education Researcher, 30(6), 487-498. https://doi.org/10.1007/S40299-021-00593-7 